\title{
Prevención y mantenimiento en la patología periodontal y periimplantaria Prevención y mantenimiento en periodoncia e implantes
}

\author{
SERRANO CUENCA V * \\ NOGUEROL RODRÍGEZ B **
}

Serrano Cuenca V, Noguerol Rodríguez B. Prevención y mantenimiento en la patología periodontal y periimplantaria. Prevención y mantenimiento en periodoncia e implantes. Av Periodon Implantol. $2004 ; 16,2: 65-79$.

\begin{abstract}
RESUMEN
Se valoran los distintos factores de riesgo en la enfermedad periodontal y periimplantaria, con el fin de establecer la prevención y control de los mismos. Se describen detalladamente los distintos métodos de monitorización del paciente, motivación, así como las diversas técnicas para el control de la placa bacteriana.
\end{abstract}

Se analizan las distintas fases del mantenimiento tanto a nivel periodontal como periimplantario.

\section{PALABRAS CLAVE}

Factores de riesgo; Prevención; Mantenimiento.
La evaluación o la determinación del riesgo en las enfermedades periodontales es un campo de gran interés para poder establecer cuáles son los factores de riesgo, cuál es la importancia de cada uno así como la asociación de varios de ellos, lo que ocurre en la mayoría de los casos. No es igual identificar a un paciente de riesgo que no ha padecido la enfermedad, que establecer el pronóstico y evolución de la enfermedad en un paciente periodontal. Los factores implicados en el inicio de la enfermedad no tienen por qué ser necesariamente los mismos que mantienen o determinan la progresión de ésta.

Valorar el riesgo en la enfermedad periodontal es intentar averiguar la probabilidad de que una persona que no tiene la enfermedad la desarrolle en un período de tiempo, y también la probabilidad de que la enfermedad progrese en un paciente que ya padecía periodontitis.

Cuando se valora el riesgo de padecer una enfermedad determinada hay que tener en cuenta la existencia de factores que hacen que la probabilidad sea mayor.

Axelson (1) clasifica los factores en varios grupos. Factores etiológicos: incluyen la placa bacteriana y la presencia de bacterias periodontopatógenas. Factores modificadores que se subdividen en factores externos o ambientales y factores internos o endógenos. Entre los factores ambientales se encuentra el hábito del tabaco, hábitos de dieta, nivel socioeconómico y cuidados dentales irregulares. Los factores endógenos son genéticos, inmunológicos, alteraciones salivales y enfermedades crónicas como la diabetes.

Algunos autores (2) no excluyen que las periodontitis se asemejan a otras enfermedades en las que los factores de riesgo y factores pronóstico no son lo mismo.

El factor de riesgo hace que aumente la probabilidad de padecer una enfermedad y cuando no aparece hace que disminuya la probabilidad de padecerla. Tiene por tanto una relación causal. Los factores de riesgo deben preceder a la aparición de la enfermedad. La elimina- 
ción de los factores de riesgo no va a curar necesariamente la enfermedad, sino que hace que disminuya la probabilidad de que se inicie la enfermedad.

Al admitirse que la enfermedad periodontal no tiene una única causa sino que es multifactorial y que las múltiples variables pueden interaccionar entre sí, hace que se desarrollen modelos de riesgo y modelos predictivos. Los modelos de predicción tienen por objeto conocer a los pacientes o dientes con mayor probabilidad de padecer la enfermedad o de que la enfermedad avance, mientras que los modelos de riesgo incluyen sólo factores de riesgo, es decir factores considerados causales.

Por tanto el objetivo será establecer un perfil de riesgo y su utilidad se resume en los siguientes puntos (3): 1 . Reducir o eliminar los factores de riesgo modificables, por ejemplo el tabaco. 2. Establecer las necesidades preventivas tanto de autocuidado como de aplicación profesional y la frecuencia de revisiones. 3. Establecer el plan de tratamiento y el mantenimiento en pacientes periodontales. 4. Evaluar el tratamiento. 5. Poderse comunicar entre profesionales y con el paciente favoreciendo su implicación y motivación.

\section{PREVENCIÓN Y CONTROL DE LAS ENFERMEDADES PERIODONTALES}

La prevención de las enfermedades periodontales se basa en el conocimiento de los factores causales. Está absolutamente demostrado que, aunque las bacterias por sí solas no son suficientes para producir la enfermedad periodontal destructiva, son esenciales para que se produzca la enfermedad periodontal de cualquier tipo, y por tanto es evidente que sin bacterias las enfermedades periodontales no existen, por lo que el control de las bacterias supone el control de la enfermedad.

Modelos de gingivitis experimental en humanos han demostrado la relación de causa-efecto entre la falta de higiene oral y la inflamación de la encía así como la reversibilidad de la situación (4). La enfermedad periodontal destructiva se caracteriza por la progresión de la inflamación a zonas más profundas del periodonto. En el establecimiento de la misma a partir de una gingivitis preexistente, tienen un gran protagonismo factores de riesgo como el tabaco y el estrés, incluso de magnitud similar a la higiene oral deficiente. Pero sin duda el factor condicionante fundamental es la predisposición genética, por lo que entra en juego el concepto de susceptibilidad individual $(5,6)$.

Por lo tanto, la prevención de las enfermedades perio- dontales no se basará sólo en la promoción de la higiene oral en la población de forma generalizada sino en la identificación de sujetos de riesgo genético con diferentes factores de riesgo ambiental antes comentado.

Actualmente el abordaje terapéutico racional y efectivo de las enfermedades periodontales comprende la obtención de unos niveles de placa bacteriana compatibles con salud para cada paciente individual. En la práctica estos se logran mediante una combinación de actuaciones terapeúticas profesionales y la colaboración del paciente con la higiene oral domiciliaria y participación en el mantenimiento o "terapéutica periodontal de soporte".

Puesto que lo que pretendemos es mejorar los niveles de higiene de los pacientes de forma mantenida, así como conseguir cambios de comportamiento, es fundamental diferenciar el concepto información sanitaria de educación sanitaria. Saber no lleva a hacer. Conseguir cambios de comportamiento implica necesariamente incorporar a los tradicionales programas de instrucción en técnicas de higiene oral, técnicas de modificación de conducta.

Un claro ejemplo es el papel que desempeña el profesional a la hora de aconsejar al paciente para que abandone el hábito tabáquico. La recomendación de dejar de fumar tiene que presentar cuatro características fundamentales:

PREGUNTAR a todos los pacientes acerca de su consumo de tabaco en cada visita y documentarlo. ¿Fuma usted? ¿Alguna vez ha intentado dejar de fumar? ¿Está interesado en dejarlo?

ACONSEJAR a todos los fumadores que abandonen su hábito. El consejo debe ser claro, firme y personalizado. Debemos recomendarle a utilizar terapéutica sustitutiva, e informarle sobre la relación entre el tabaco y la salud.

AYUDAR al paciente a dejar de fumar, fijando una fecha para dejarlo, proporcionándole literatura de apoyo y creándole un ambiente favorable (en la clínica nadie fuma). Para ayudarle es necesario que revisemos con el paciente experiencias anteriores. PROGRAMAR una visita de seguimiento 1-2 semanas después de la fecha en la que han decidido dejar de fumar. Los estudios indican que el porcentaje de fumadores que consiguen abandonar su hábito aumenta al doble cuando se mantienen contactos de seguimiento de forma rutinaria con los pacientes interesados en ello. La mayoría de los fumadores emprenden varios intentos de dejar de fumar antes de finalmente conseguirlo, por lo que las recaídas son un componente normal del proceso. 

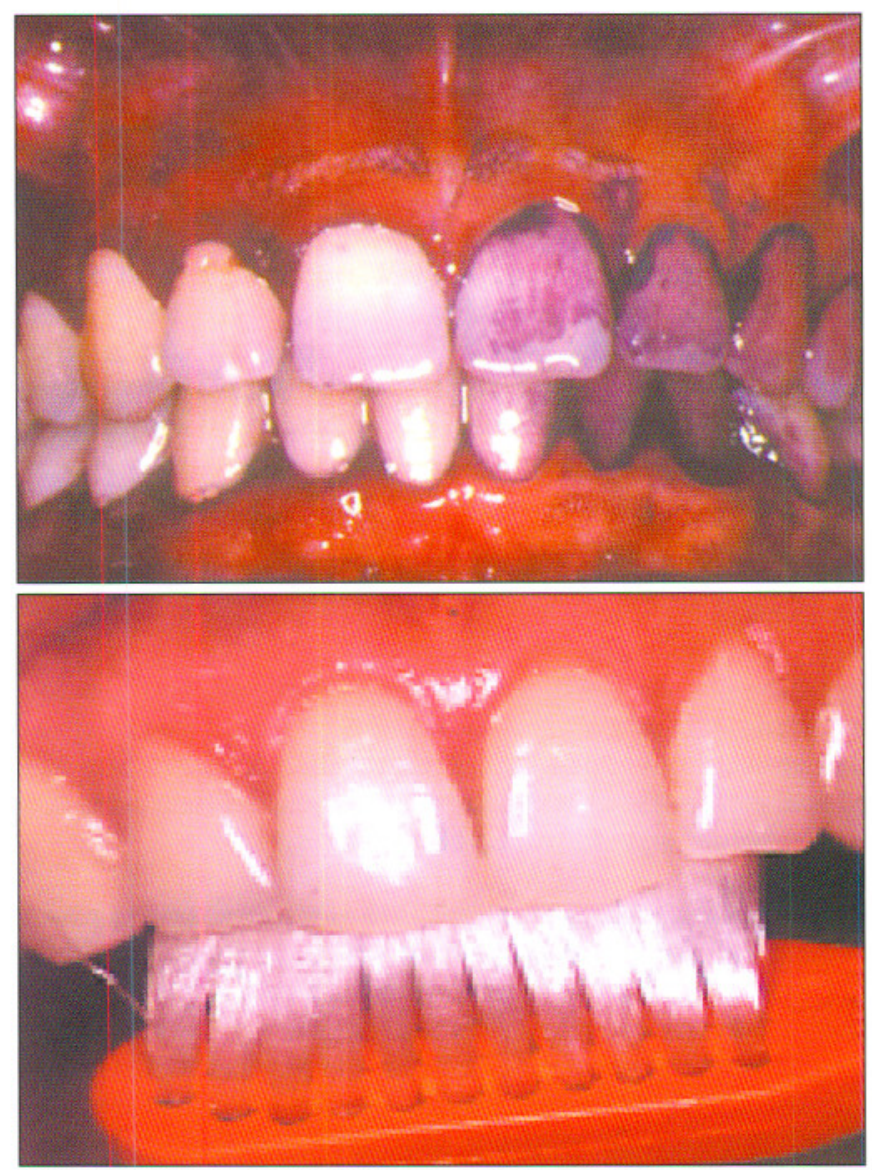

Fig. 1. Control de placa bacteriana.

Por lo tanto, cuando un individuo se propone cambiar parte de su estilo de vida, según Hernán (7) deben darse un conjunto de circunstancias que se consideran predisponentes: Información e interés. Sentir la necesidad de cambiar. Tomar la decisión. Clarificar la información y aprender los procedimientos, para lo que necesitará medios y tiempo.

Por lo tanto y siguiendo las teorías sobre el aprendizaje en salud recogidas en el modelo cognitivo-social (MCS) (8) y aplicadas en la consulta periodontal debería incluir los siguientes pasos: Asunción del problema por parte del paciente. Definición del papel del profesional y del paciente. Estrategias de actuación. Adquisición de destrezas. Transformación de las destrezas en hábitos. Valoración de los resultados del tratamiento.

Cada uno de estos pasos se cumplen en diferentes entrevistas entre el profesional y el paciente. Consideramos de especial importancia la primera visita, pues en ella se producen hechos de gran relevancia posterior. En la misma se va a producir el primer contacto entre paciente y profesional, la primera e importante transmisión de información y se van a
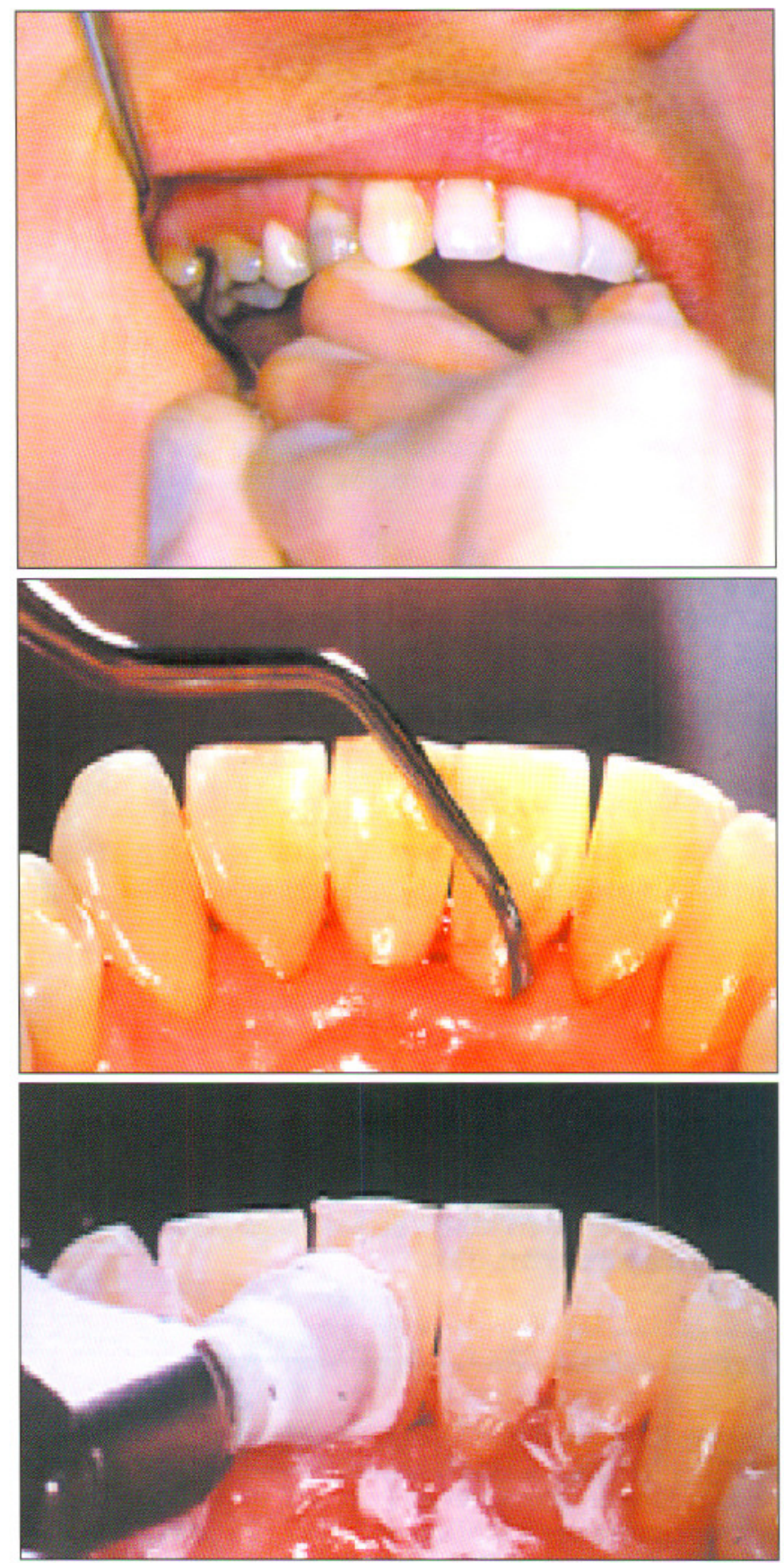

Fig. 2. Distintos procedimientos profesionales para el control de la placa bacteriana.

definir los papeles de actuación. La instrucción y motivación deben realizarse antes de cualquier tipo de tratamiento. En la motivación se utilizarán diversos argumentos en función de las necesidades percibidas del paciente, tales como que la pérdida de dientes disminuye la función, la estética personal, factores sociales (halitosis, dientes sucios, etc.), así como la repercusión de la enfermedad en la salud general del paciente. 
A continuación pasamos a exponer las principales medidas preventivas para el control de las enfermedades periodontales:

\section{Control mecánico de la placa bacteriana perio- dontopática}

Los métodos preventivos más ampliamente aceptados son los que combinan medidas de higiene oral personal y profesional (Figuras 1 y 2 ), entendiendo que el control de placa supragingival pertenece al individuo y la eliminación de la placa subgingival y el cálculo se consigue a través de las profilaxis profesionales periódicas (9).

Está demostrado que esta combinación previene el inicio y progresión de las enfermedades periodontales.

No vamos a describir cada una de las técnicas,pues no es objeto de esta ponencia, pero si debemos recordar lo imprescindible de una buena técnica de cepillado bien manual o con cepillos eléctricos, que en las dos últimas décadas han sufrido muchas modificaciones en sus diseños incluyendo movimientos de oscilación, rotatorios y cepillos que se mueven a alta frecuencia. Hoy día se consideran superiores a los manuales en que realizan una mejor remoción de placa del área interproximal.

La limpieza del área interdental es imprescindible, por lo que utilizaremos la seda y la cinta dental cuando la papila ocupa el espacio interdental, y en los pacientes con periodontitis en los que los espacios interdentales están abiertos son imprescindibles los cepillos interproximales.

\section{Control químico de la placa bacteriana}

Puesto que las enfermedades periodontales están producidas por bacterias, es adecuado sugerir la utilización de quimioterápicos, con el fin de eliminar la microbiota oral, inhibir la colonización bacteriana en la superficie de los dientes, eliminar la placa establecida e impedir la mineralización de la placa.

En relación a las enfermedades periodonales estos antimicrobianos los dividimos en agentes frente a la placa supragingival, que previenen la formación de placa y se utilizan para prevenir y tratar la gingivitis crónica (prevención de la enfermedad); mientras que los agentes contra la placa subgingival, utilizados en el tratamiento de las periodontitis, como los antibióticos, estarían fuera de la prevención y sí dentro del tratamiento.

El control químico supragingival puede ser llevado a cabo por una serie de antimicrobianos, entre los que destacamos la clorhexidina. Igualmente los compuestos fenólicos también se han demostrado eficaces como agentes preventivos, como el triclosán cuando se combina con citrato de cinc.

La utilización del control químico también va a ser muy útil cuando el control mecánico es inadecuado, o para sustituir a éste en determinadas circunstancias como después de la cirugía periodontal, determinadas gingivitis en las que el dolor impide el cepillado, o en pacientes discapacitados.

\section{Eliminación de factores que retienen la placa bac- teriana}

Igualmente de importante en la prevención de las enfermedades periodontales está el controlar aquellas situaciones que van a dar lugar a retención de placa y que si no se remedian antes del tratamiento periodontal serán un factor recurrente.

Destacamos los dientes en mala posición, como en el caso de los apiñamientos dentarios. La forma de contacto de los dientes, fundamentalmente cuando se realiza una odontología restauradora y protésica deficiente, en la que se favorece la impactación alimentaria. Igualmente la aparatología de ortodoncia favorece el acúmulo de placa y dificulta un adecuado control de esta. Los movimientos dentarios pueden inducir lesiones, incluso irreversibles, en el periodonto (10). No se debe comenzar bajo ningún concepto un tratamiento ortodóncico sin tener en cuenta el estado periodontal. Si existen problemas periodontales se deben subsanar primero estos y luego estando en contacto con el ortodoncista comenzar dicho tratamiento.

\section{LA ENFERIMEDAD PERIODONTAL COMO FACTOR DE RIESGO DE OTRAS ENFERMEDADES SISTEMMICAS}

Estudios detallados y contrastados han puesto de manifiesto que las enfermedades periodontales, como infecciones crónicas, pueden desempeñar un papel coadyuvante en diversas enfermedades sistémicas importantes, entre las que se han incluído la enfermedad cardiovascular y la arteriosclerosis. La explicación sería que la exposición crónica a las bacterias periodontales y las endotoxinas y citoquinas de origen periodontal favorecería la formación de ateromas, considerándose que podrían tener la misma magnitud que factores de riesgo clásicos como el colesterol.

También se ha observado que determinados patógenos 
periodontales como A. Actinomycetemcomitans se han visto implicados en procesos de endocarditis infecciosa, por su especial capacidad para adherirse a las válvulas cardíacas o a las paredes del endocardio (11).

Existe una clara evidencia que la enfermedad periodontal no controlada aumenta el riesgo de tener un recién nacido prematuro de bajo peso. La explicación sería que determinados productos asociados a la destrucción periodontal, tendrían un comportamiento similar con sustancias que desencadenan el parto como las prostaglandinas (11).

Por todo lo anteriormente expuesto, el control de las enfermedades periodontales puede tener una gran importancia en salud pública.

\section{SALUUD PÚBLICA Y ENFERMEDĀD PERIODONTAL}

Los autores que han estudiado la prevención y el control de las enfermedades periodontales a nivel comunitario $(12,13)$ recomiendan una estrategia poblacional dirigida a fomentar la responsabilidad individual sobre la propia salud periodontal a través de educación para la higiene oral.

Echeverría y Manau (9) proponen algunos métodos tales como educar a la población sobre los signos y síntomas de enfermedades periodontales que permita al individuo susceptible conocer lo antes posible cuándo es necesario recabar ayuda profesional. Detectar en las revisiones escolares los posibles casos de periodontitis de inicio temprano e incluir a estos individuos en programas específicos. Establecer programas preventivos comunitarios de mantenimiento periodontal profesional para grupos de riesgo conocidos como son mujeres embarazadas, disminuídos, diabéticos, enfermos de Sida, etc. Investigar sobre métodos sencillos para detectar a los individuos con riesgo alto de presentar periodontitis grave.

\section{MANTENIMIENTO PERIODONTAL}

El mantenimiento es imprescindible en el éxito a largo plazo del tratamiento periodontal. Sin mantenimiento, cualquier tratamiento por muy bien que se haya realizado fracasará.

No hay que olvidar que una parte de los pacientes deja de asistir con el tiempo a las visitas de mantenimiento. No hay que entender que en todos los casos estén descontentos con nosotros, es posible que influya más una cierta inconstancia y pérdida de interés hacia el problema, asociado al hecho de que muchos pacientes piensan al pasar el tiempo y ver que se encuentran bien, que se han curado (14).

Pero también es obligación nuestra que el paciente vea que el mantenimiento es "mucho más que una limpieza de boca". Debemos interrogar periódicamente al paciente sobre su actitud respecto al problema y a nuestra actuación. Por ello deberemos recordar la cita sin dejarnos influir por el "yo llamaré".

Por todo ello, en la práctica diaria seremos auténticos actores de educación sanitaria con nuestros pacientes. Los protocolos de actuación clínica deben estar bien reglados, pues con ello transmitiremos al paciente sensación de organización y nos va a permitir cumplir una serie de objetivos previamente establecidos.

\section{Los objetivos serán los siguientes:}

1. Reevaluar la situación periodontal del paciente en el momento.

2. Instrucción sobre higiene y remotivación sobre el problema.

3. Intervenir para corregir las zonas de actividad de la enfermedad.

\section{Reevaluación}

\section{A. Recepción del paciente}

Realizaremos una verificación de la situación afectiva del paciente sobre su problema y su relación con nosotros. Comprobaremos si ha surgido algún elemento distractor como sensibilidad, hemorragia, dolor, etc. En caso de que en la historia clínica tuviésemos registrado algún problema por el que el paciente se interesó especialmente y que no hubiera quedado definitivamente resuelto, deberá ser el primero por el que preguntemos, de esa forma verá que no nos olvidamos del mismo y se sentirá tratado de forma personal.

\section{B. Determinación y registro de los indicadores periodontales (Figura 3)}

a. Indice de placa con revelador

b. Indice de hemorragia al sondaje

C. Profundidad de bolsa. Sondando con más interés:

- las bolsas que tenían antes del tratamiento más de 5 $\mathrm{mm}$ 


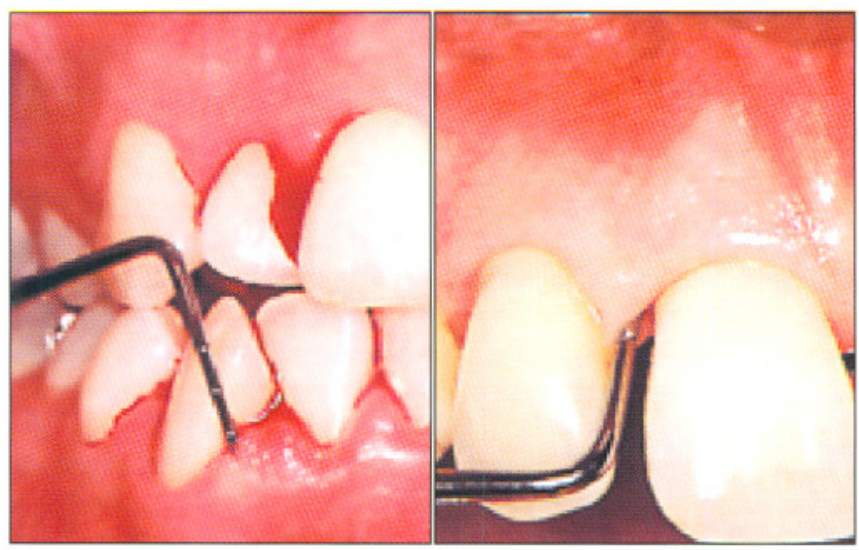

Fig. 3. Sangrado al sondaje periodontal y medición de la profundidad de bolsa.

- que en la revisión anterior habían mostrado aumento de más de $2 \mathrm{~mm}$ de profundidad

- hemorragia persistente

D. Recesión. Valorando las zonas con falta de encía insertada y las que hayan recibido tratamiento mucogingival.

D. Movilidad. Compararla con los registros anteriores. Prestar especial interés a la de los dientes que puedan ser o son pilares de puentes, o los que tengan una situación oclusal compleja.

\section{Instrucción}

\section{A. Remotivación del paciente}

Es un tiempo muy importante pues haremos un recordatorio de los conocimientos del paciente sobre su enfermedad. En éste momento le mostraremos al paciente la evolución de los registros obtenidos de su boca (placa, hemorragia, bolsas, radiografías), y con el espejo en la mano le enseñamos en su propia boca los aspectos más destacables. También es bueno dar información al paciente sobre avances en el conocimiento de las periodontitis.

\section{B. Instrucción de higiene}

Reforzamiento del hábito de higiene y de la técnica de realización. Hemos de tener en cuenta que suele haber una recaída con el paso del tiempo. Por ello suele ser interesante el mostrarle al paciente el registro de placa obtenido.

\section{Intervención}

Será la parte del mantenimiento periodontal a la que dediquemos el mayor tiempo, aproximadamente la mitad del tiempo total.

\section{A. Tartrectomía}

La mayor parte de los pacientes presentan un cierto acúmulo de cálculo supragingival, sobre todo en la zona lingual del sextante 5. Este cálculo es blando todavia y está poco adherido al diente por lo que se elimina bien con ultrasonido.

\section{B. Raspado y alisado radicular}

Es difícil que se haya acumulado cálculo subgingival bien estructurado en los $4 \circ 6$ meses transcurridos desde el último mantenimiento, por lo que se trata de alisar raíces que empiezan a estar algo rugosas. Para ello trabajaremos con curetas muy bien afiladas. Con la sonda iremos detectando las "áreas problema" y las iremos alisando. Siempre deberemos alisar las zonas con hemorragia aunque parezca que están lisas, sobre todo si en registros anteriores ya habían mostrado sangrado.

\section{Pulido}

Es el final de una visita de mantenimiento. El pulido nos permite crear una superficie supragingival muy lisa. Como las bacterias periodontopatógenas se adhieren mal a las superficies lisas, éste es un mecanismo muy importante de control de la periodontitis, aunque se olvida con frecuencia. El pulido debe hacerse con copas de goma especiales y pasta abrasiva a baja velocidad.

\section{Frecuencia de visitas de mantenimiento}

En el caso de pacientes con gingivitis se debe realizar un mantenimiento rutinario cada 6 meses.

En el caso de pacientes con periodontitis, si esta es moderada (bolsas $<6 \mathrm{~mm}$ ), el mantenimiento periodontal debe realizarse cada 4 meses, no obstante después de dos años de buen control, puede realizarse cada 6 meses.

En pacientes con periodontitis avanzada (bolsas $>6 \mathrm{~mm}$ ), si después de los tratamientos oportunos la enfermedad está inactiva, se pasará a un programa de visitas cada 4 meses, y se continuará de igual forma que en las periodontitis moderadas. Ahora bien, si después de todos los tratamientos efectuados, persistiera la actividad de enfermedad en las periodontitis avanzadas, el mantenimiento será cada 3 meses. Sólo después de tres años de buen control, pasaremos a un mantenimiento cada 4 meses. 
LA PREVENCIÓN DE LA PATOLOGÍA PERIIMPLANTARIA deberá realizarse a dos niveles: por una parte controlar o eliminar los factores de riesgo de aparición de patología periimplantaria; y por otra la monitorización para el diagnóstico precoz de cualquier patología periimplantaria, fase esta que se realizará durante las visitas de mantenimiento cuya periodicidad dependerá del grado de control por parte del profesional responsable del tratamiento de los factores de riesgo.

Hemos de tener en cuenta que la presencia de infección en los tejidos periimplantarios no implica que el implante fracase (15), entendiendo de forma absoluta por implante fracasado aquel que debemos retirar de la boca del paciente en que fue colocado.

La mayor incidencia de los procesos periimplantarios se observó en el período próximo a la implantación ( 0 a 120 días ). Esta observación indica una mayor pérdida de implantes en el período de cicatrización o en el comienzo de la carga .

Así mismo los datos reflejan que las pérdidas de implantes disminuyen con el tiempo, mientras que la incidencia de enfermedad periimplantaria aumenta con el tiempo (16).

A continuación analizaremos los distintos factores de riesgo que hemos de tener en cuenta para prevenir las distintas complicaciones, y en definitiva saber qué grado de compromiso están dispuestos a asumir tanto el profesional como el paciente.

\section{TÄBĀCO}

Diferentes autores han demostrado un porcentaje significativamente mayor de fracaso de implantes ocurrido en fumadores comparado con no fumadores $(17,18)$ siendo mayor el riesgo de desarrollar una periimplantitis en los fumadores.

Igualmente se ha observado una mayor dificultad en la cicatrización y un importante efecto perjudicial en el estado periodontal (18). El tabaco está asociado con niveles significativamente mayores de pérdida ósea marginal e inflamación de los tejidos blandos.

Bain (19) ha analizado en un estudio prospectivo el efecto de un protocolo para el cese del tabaco en el éxito de los implantes. En el protocolo se informa a los pacientes del riesgo que supone fumar para el fracaso de los implantes. Así mismo se le indica del cese completo del hábito desde una semana antes de la cirugía hasta las 8 semanas después. Los resultados indican que aquellos pacientes que han cum- plido estrictamente el protocolo presentan un índice de fracaso similar al de los pacientes no fumadores y significativamente menores que los pacientes fumadores que no siguieron el protocolo. Diversos autores $(20,21)$ consideran que existiría un efecto sinérgico entre una mala higiene oral y el hábito tabáquico, con una mayor pérdida de hueso marginal en implantes integrados con éxito. Se piensa que el efecto negativo que produce el tabaco se debe a los cambios que éste produce sobre el organismo, por su efecto sistémico y local. Estudios experimentales (22) ponen de manifiesto modificaciones en la microvascularización de la mucosa oral después de la administración sistémica de nicotina.

\section{PLACA BĀCTERIANA}

El factor etiológico principal en el desarrollo de una mucositis y/o periimplantitis es la infección por bacterias patógenas de la placa bacteriana, debido a la capacidad que tienen de alterar la adhesión del epitelio de unión (23). Los tejidos blandos periodontales y periimplantarios responden de igual forma ante el depósito inicial de placa bacteriana, sin embargo cuando el depósito se prolonga en el tiempo, la extensión apical es más pronunciada en la mucosa periimplantaria .

La microflora presente en la cavidad oral antes de la colocación de los implantes va a determinar la composición de la nueva microbiota que se va a formar alrededor de los mismos.

La microbiota que encontramos en el entorno periodontal y periimplantario es similar tanto en estados de salud como en presencia de patología. Cuando no existe ningún tipo de patología la flora está compuesta por cocos Gram + y bacilos inmóviles tanto en implantes $(24,25)$ como en dientes $(26)$. En situaciones patológicas la flora en ambos casos estará compuesta por bacterias anaerobias Gram -, aumentando el porcentaje de bacilos móviles, fusiformes y espiroquetas ( Prevotella intermedia, Fusobacterium nucleatum, Porphyromona gingivalis, Capnocytophaga) $(26,27)$.

En pacientes edéntulos totales con implantes la microflora se asemeja bastante a la de un periodonto sano. En pacientes edéntulos parciales con implantes, los patógenos periodontales se transmiten desde las bolsas periodontales de los dientes remanentes al surco periimplantario, lo que sugiere que los dientes naturales se comportan como reservorio de gérmenes que luego invadirán los implantes provocando mayor índice de fracaso (28).

Es por tanto necesario corregir todos los problemas 
periodontales antes de la colocación de implantes ya que diversos estudios han demostrado que los pacientes desdentados que habían perdido sus dientes por enfermedad periodontal tienen menos tasa de éxito que los desdentados sin historia periodontal previa (29).

Hoy día existen evidencias que asocian formas severas de enfermedad periodontal y patología periimplantaria con pacientes que parecen responder, a los cambios bacterianos producidos por la microflora patógena periodontal, con una producción aumentada de mediadores de la inflamación como la prostaglandina E2 y la interleuquina 1, hablándose de un fenotipo hiperinflamatorio (30).

\section{SOBRECARGA BIOMECÁNICA}

La carga oclusal puede afectar tanto a la histointegración como a la reconstrucción protética. En un implante que todavía no está sometido a carga encontramos siempre un hueso periimplantar con disposición horizontal. Cuando se establece la funcionalización de ése implante la necesaria formación de una anchura biológica adecuada provoca una discreta reabsorción ósea periimplantaria en forma de cuña sin ningún tipo de significado patológico.

Si ése implante recibe una carga biomecánica excesiva se van a provocar una serie de microfracturas en la interfase hueso-implante a nivel coronal y consecuentemente una reabsorción ósea. Las fuerzas paraaxiales incrementan el estrés entre el implante y el hueso cortical, aumentando las zonas de tensión y compresión en el hueso crestal periimplantario (31).

En estudios experimentales in vivo se ha observado que la sobrecarga oclusal origina la pérdida de una parte $\circ$ de todo el hueso periimplantario. En estos estudios se demuestra además que es mucho más nocivo la sobrecarga oclusal que el acúmulo de placa bacteriana $(32,33)$. Se ha observado en los fracasos implantarios debidos a sobrecarga oclusal que la microflora predominante eran estreptococos. Igualmente se ha sugerido que el progreso de la enfermedad periimplantaria en implantes ya osteointegrados y en carga se deba a sobrecarga biomecánica, a una infección marginal o a una combinación de ambos (34).

Es importante en la planificación protética el número y posición de los implantes, pues una misma prótesis con la misma carga oclusal puede ejercer diferentes niveles de estrés sobre los implantes y sobre el hueso de soporte, dependiendo del número de implantes y de la configuración en la que sean colocados.
La altura de la restauración implantosoportada varía según sea el espacio interarcadas en la zona edéntula.Cuando éste es muy amplio se genera un aumento del momento de fuerza que actúa sobre los implantes. Esta relación implante prótesis desfavorable constituye un factor de riesgo que contribuye a la fractura de la prótesis y a una excesiva pérdida ósea periimplantaria.

Se considera que un espacio interarcadas, en la zona edéntula inferior a $6 \mathrm{~mm}$ constituye un factor de riesgo para el diseño de la prótesis (35).

El bruxismo es uno de los hábitos orales más frecuentes que producen fuerzas parafuncionales. Aunque el bruxismo no es una contraindicación de implantes, sí es un factor de riesgo que debe tenerse en cuenta, ya que influye en la planificación del tratamiento en el paciente candidato a implantes(36).

\section{FACTORES ÓSEOS}

La calidad y cantidad ósea son factores que influyen en la supervivencia del implante. La densidad ósea es más importante que el volumen de hueso en cuanto al pronóstico para la integración del implante (37). La baja densidad ósea en el lugar de colocación del implante (hueso tipo IV) se ha asociado con un riesgo aumentado de fracaso de los implantes en estudios retrospectivos y prospectivos $(38,39)$.

Debido a que el maxilar superior presenta una más baja calidad ósea que la mandíbula se ha sugerido que esto explica el mayor número de implantes fracasados en éste maxilar.

Se ha observado que la pérdida ósea periimplantaria es menor en aquellos pacientes que presentan una cresta ósea mínimamente reabsorbida en el momento de la colocación del implante, respecto a pacientes que muestran una extensa reabsorción ósea.

\section{TEJIDOS BLANDOS}

La ausencia de encía queratinizada fue considerada como un factor riesgo para el mantenimiento de los implantes (40). Sin embargo otros autores (41) observaron clínicamente que ni la ausencia de encía queratinizada, ni la anchura de la misma influyen significativamente en el control de la placa, en el índice de hemorragia o en la profundidad de sondaje, no siendo un requisito previo para el mantenimiento de la salud gingival si los pilares se limpian correctamente (Figura 4). 

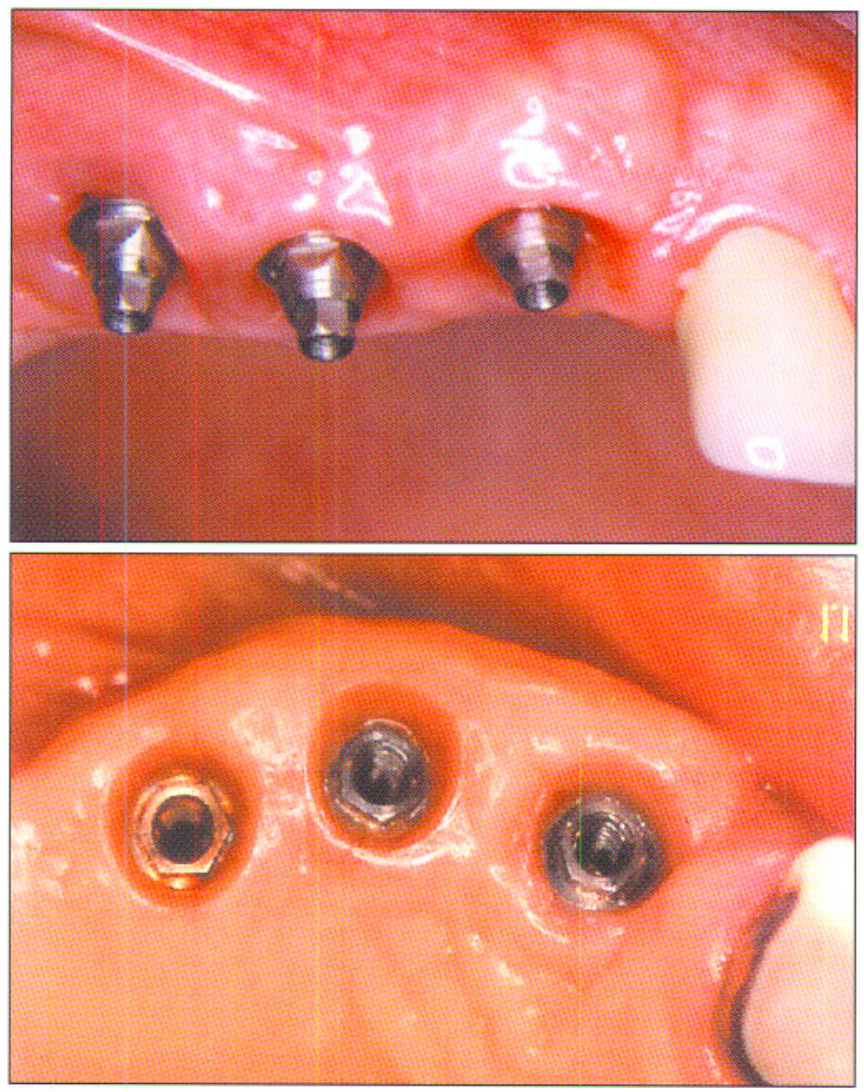

Fig. 4. Exploración de tejidos blandos periimplantarios sanos.

No obstante a pesar de que no influye en la supervivencia del implante actualmente se considera que debe de existir una banda de $2 \mathrm{~mm}$ o más de encía queratinizada.

\section{RADIOTERAPIA Y QUIMIOTERAPIA}

La irradiación de los maxilares origina cambios en el hueso y en los tejidos blandos. Entre otros existe desmineralización ósea, susceptibilidad a las infecciones, retraso en la cicatrización de las heridas y necrosis avascular. La radioterapia no supone una contraindicación para el tratamiento con implantes, en pacientes que presentan cánceres de cabeza y cuello (42). Se considera no obstante que es mejor su colocación antes de la irradiación, y que para disminuir los riesgos de fracaso en algunos estudios se ha sugerido la administración de oxígeno hiperbárico (43).

Después de la radioterapia debe dejarse un período mínimo de 5 meses hasta la colocación de los implantes. La rehabilitación protésica debe ser implantosoportada, sin que exista apoyo en la mucosa, por el peligro de desarrollar úlceras.
Los pacientes sometidos a quimioterapia son de alto riesgo para la implantología y padecen complicaciones severas (44).

\section{ENFERMEDADES SISTÉMICAS}

Diversos estudios clínicos tanto retrospectivos (45, 46) como prospectivos consideran que los pacientes con diabetes mellitus controlada, presentan una frecuencia de éxito similar a la población normal.

La osteoporosis es otra de las alteraciones con las que se enfrenta el implantólogo. Los cambios que se producen en los maxilares son similares a los de otros huesos del organismo. La masa ósea trabecular siempre resulta más afectada que el hueso cortical. Algunos autores (47) observan experimentalmente que la formación de hueso periimplantaria es menor cuando existe osteoporosis que en el grupo control, por ello se requerirán implantes de mayor superficie para conseguir el mismo grado de contacto existente entre un implante y el hueso normal.

Analizado uno de los pilares que sustentan la prevención de la patología periimplantaria, como es el control de los factores de riesgo, pasaremos a analizar el otro pilar fundamental que es el MANTENIMIENTO.

La salud óptima alrededor de los implantes a largo plazo dependerá de la inhibición de la formación de la placa, prevención de su adhesión, eliminación de la misma y control de la actividad de la enfermedad periodontal.Es por ello necesario un adecuado protocolo de reevaluación y mantenimiento, que deberá consistir en:

\section{REEVALUACIÓN CONTINUADA $(48,49,50)$}

\subsection{Examen clínico}

Es recomendable un exámen clínico anual. Durante el mismo realizaremos:

- Inspección y palpación de tejidos blandos periimplantarios, lo que nos permitirá detectar la presencia de inflamación, exudado o supuración (Figura 5).

- Sondaje: se ha debatido mucho y existe controversia en la actualidad sobre la conveniencia, tanto desde un punto de vista patogénico como práctico, de realizar sondaje o medición del nivel de detención de la sonda (NDS) (Figura 6). Recordando que el nivel en el que la sonda se detiene puede ser un buen indicador del nivel óseo (1,4 mm más apical ), 


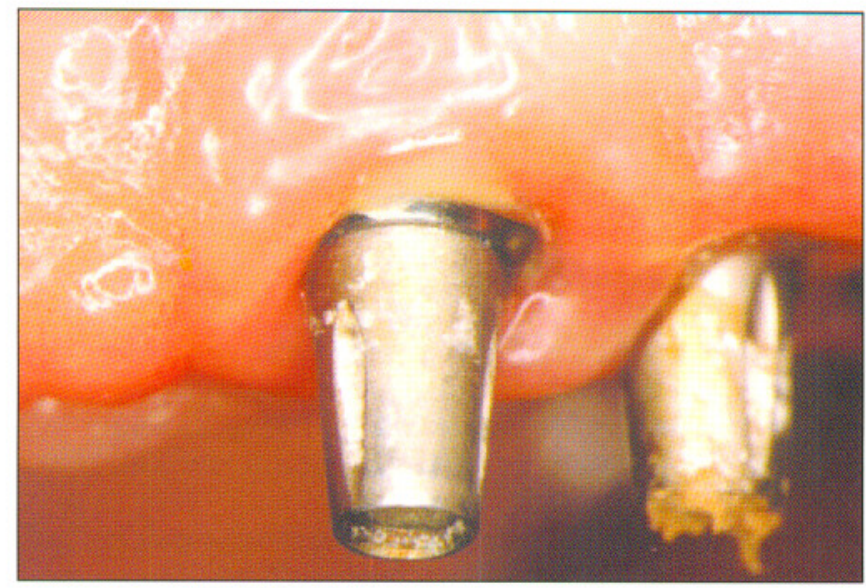

Fig. 5. Tejidos periimplantarios enfermos.
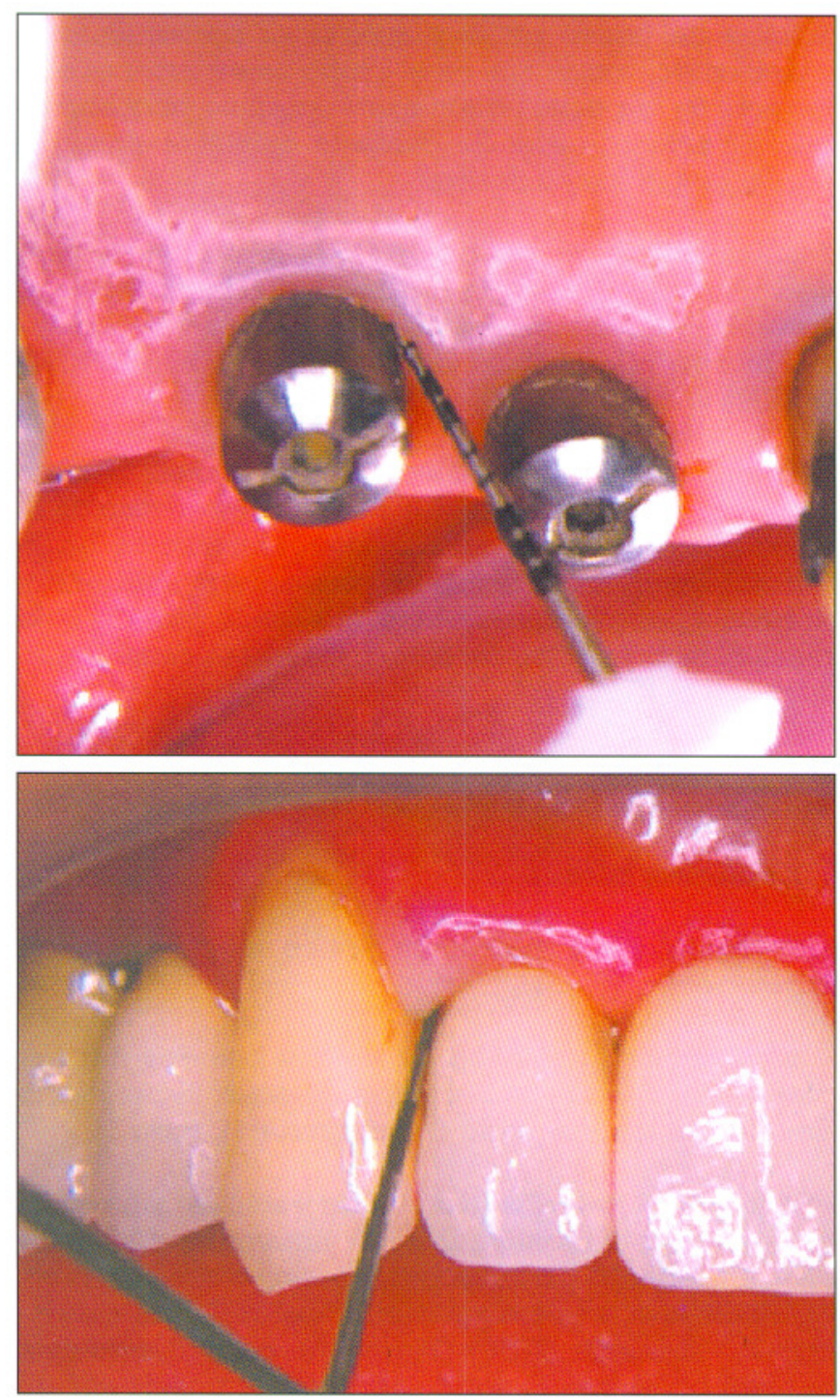

Fig. 6. Sondaje con prótesis desmontado y sin desmontar.
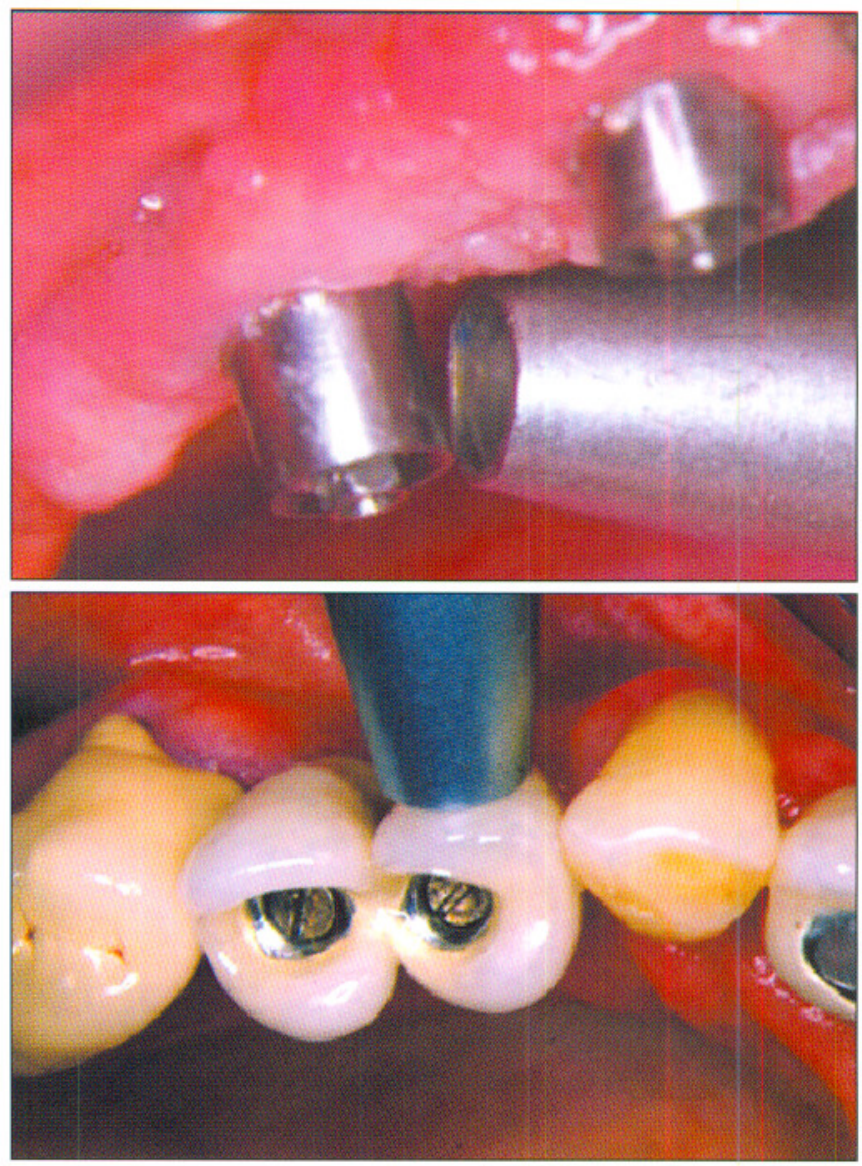

Fig. 7. Exploración de la movilidad con el Periotest, con prótesis montada y desmontada.

podría ser recomendable éste tipo de exploración, con sonda de plástico, en los casos en que la morfología de la prótesis lo permita, realizando menor presión que en el sondaje dental. No sondaremos nunca en los tres primeros meses tras la conexión del elemento transmucoso ( tanto en las cirugías de una fase quirúrgica como en la de dos fases) para no interferir en el proceso de cicatrización.

- Valoración de la movilidad de los pilares con la prótesis desmontada, para lo que estudios recientes abogan la utilidad del Perio-test (Figura 7).

\section{- Examen oclusal}

- Comprobación del apretado de tornillos que sujetan la prótesis en los casos donde no se observa nada anormal y no deseamos desmontarla.

\subsection{Examen radiológico}

- La valoración del nivel del hueso alrededor del implante ha mostrado ser uno de los sistemas más valiosos para valorar el estado de los implantes. 


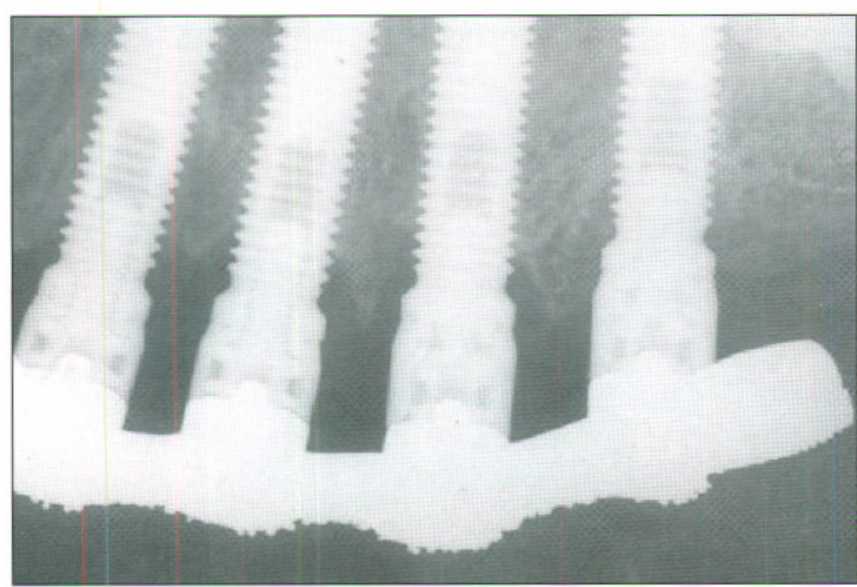

Fig. 8. Exploración radiográfica de implantes osteointegrados.

- Realizaremos dos radiografías periapicales, con $12^{\circ}$ de divergencia horizontal y técnica de paralelización, en cada una de las fijaciones. En el caso de implantes roscados, para considerar válidas dos radiografías, las estrías deberán ser claramente visibles y tener la misma longitud y apariencia (Figura 8).
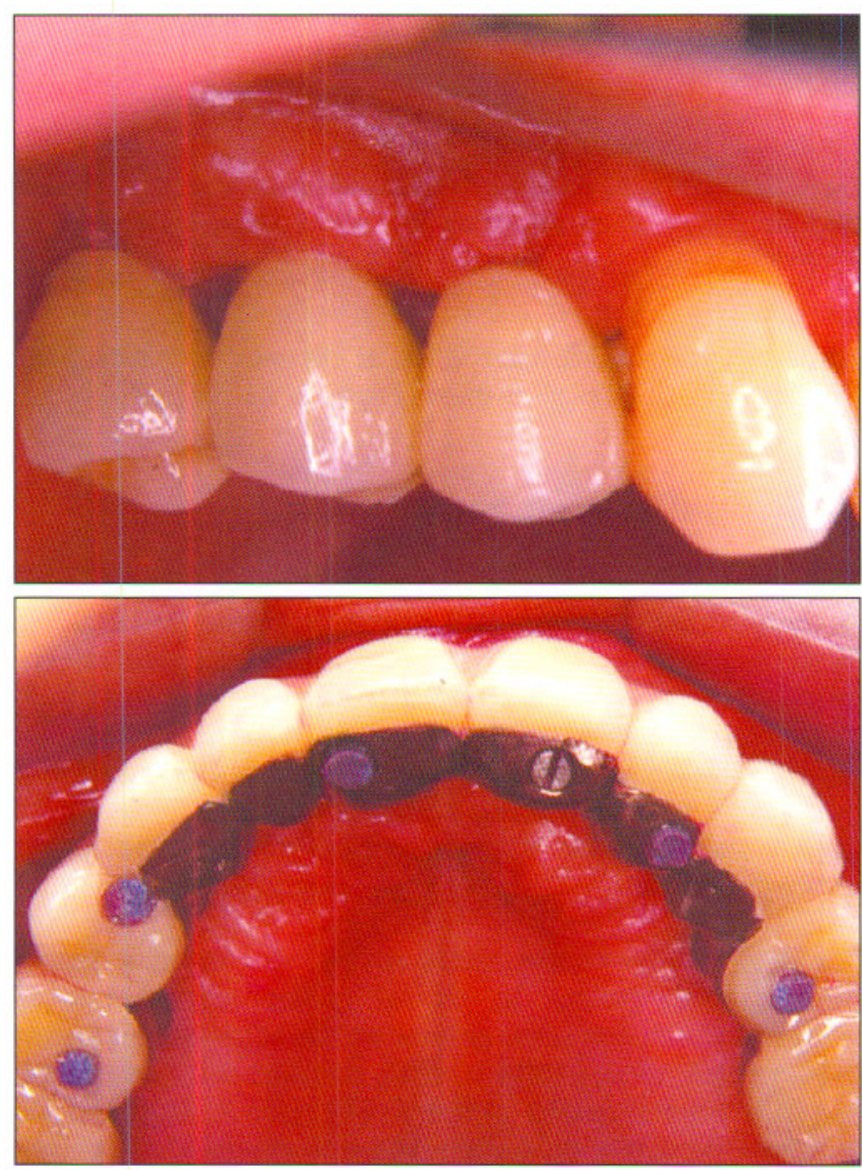

Fig. 9. Exploración de los tejidos blandos alrededor de prótesis implantosoportadas.

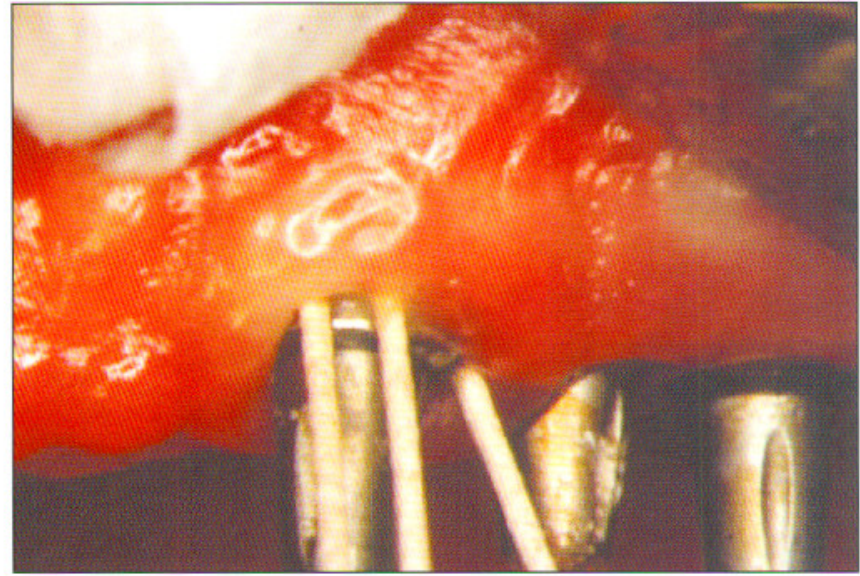

Fig. 10. Estudio microbiológico en periimplantitis.

- La frecuencia de éste exámen radiográfico si no aparecen complicaciones será la siguiente: conexión del elemento transmucoso, colocación de la prótesis, 6 meses tras la colocación de la prótesis, anualmente durante los tres primeros años y a partir del tercer año, cada dos años.

- Se considera que el implante está en perfectas condiciones cuando un año después de su inserción se aprecia una pérdida ósea horizontal de aproximadamente $1,5 \mathrm{~mm}$ y en los años sucesivos $0,1-0,2 \mathrm{~mm}$.

\subsection{Examen microbiológico}

- Hoy día existen pruebas diagnósticas rápidas para detectar la presencia de determinados patógenos en el surco periimplantario y están adquiriendo creciente importancia en el control del paciente de implantes. No obstante, aún no puede establecerse la necesidad de una valoración microbiológica periódica (Figura 10).

\section{MANTENIMIENTO PERIÓDICO $(49,50)$}

\subsection{Actuación profesional}

- Examinar y evaluar los tejidos periimplantarios (Figura 9).

- Instruir y motivar al paciente para que tenga una correcta higiene oral, para lo cual nos será muy útil el empleo de indicadores y reveladores de placa.

- Eliminación de los depósitos blandos y duros que se hayan formado alrededor de los implantes, prótesis o dientes remanentee. En el caso de los implantes deberemos emplear instrumental que por su compo- 


\section{AVANCES}

Volumen 16 - No 2 - Agosto 2004
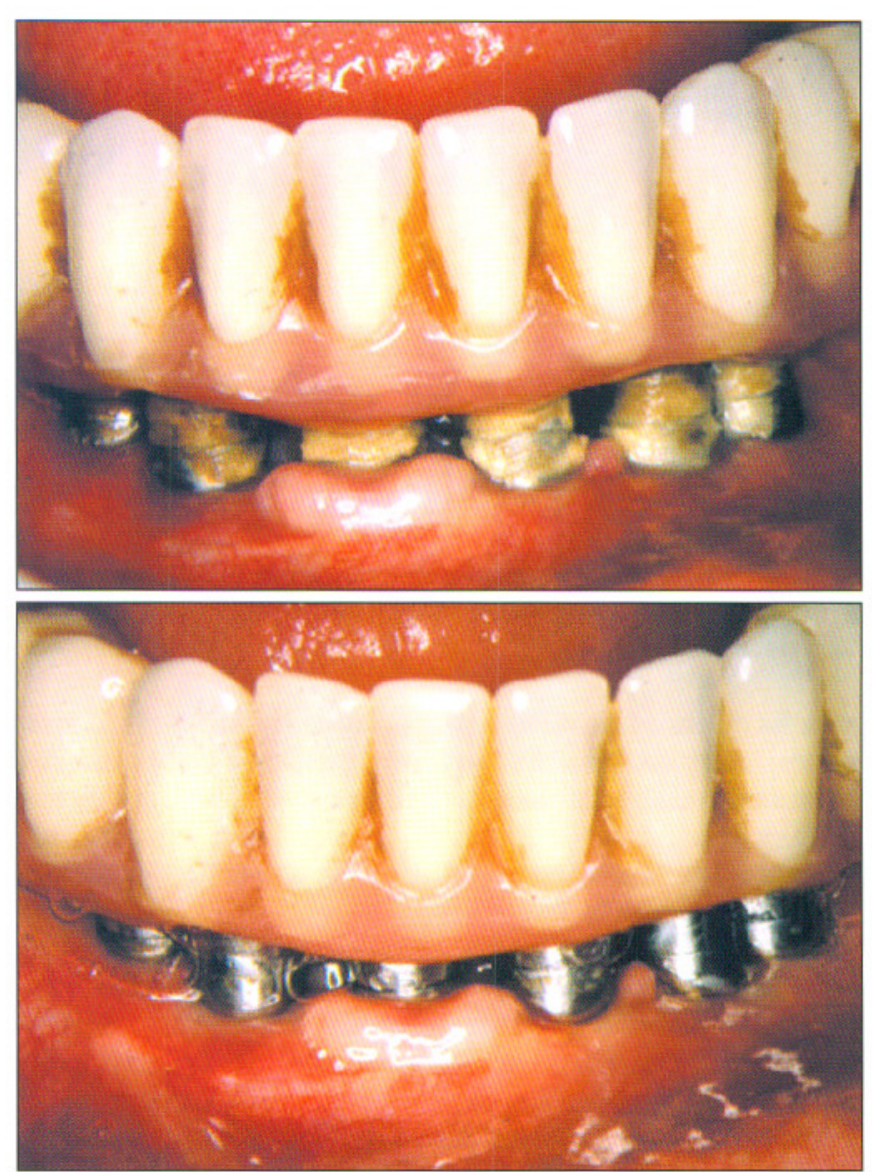

Fig. 11. Estado de los pilares de implantes antes y después del mantenimiento.

sición y dureza no altere la biocompatibilidad de la capa de óxido de titanio ni ralle la superficie metálica de los diferentes elementos que forman la prótesis. Utilizaremos raspadores y curetas metálicas recubiertas de metales o aleaciones nobles, de plástico, de teflón y de cerámica. Las curetas de plástico hoy por hoy son los instrumentos más recomendados por la mayoría de los investigadores. En relación a los aparatos de limpieza ultrasónica y sónica, se intentó que para evitar el problema del rayado del titanio las puntas fueran totalmente de plástico. Sin embargo la transmisión de impulsos y la vibración no eran las adecuadas y sus resultados no fueron los apetecibles. Las últimas puntas para tratamient de los implantes son de material cerámico. Son más rígidas, transmiten mejor la vibración y son más blandas que el titanio. Los aparatos de chorro de bicarbonato están totalmente contraindicados, ya que el bicarbonato a presión desgasta rápidamente el titanio. El pulido de la superficie lo realizaremos con pastas de pulido de abrasividad baja y que no presenten flúor en su composición. Siempre hay que aplicarlas con copa o puntas de goma. No obstante, es difícil eliminar cálculo de un pilar altamente pulido sin rayarlo, por lo que debe
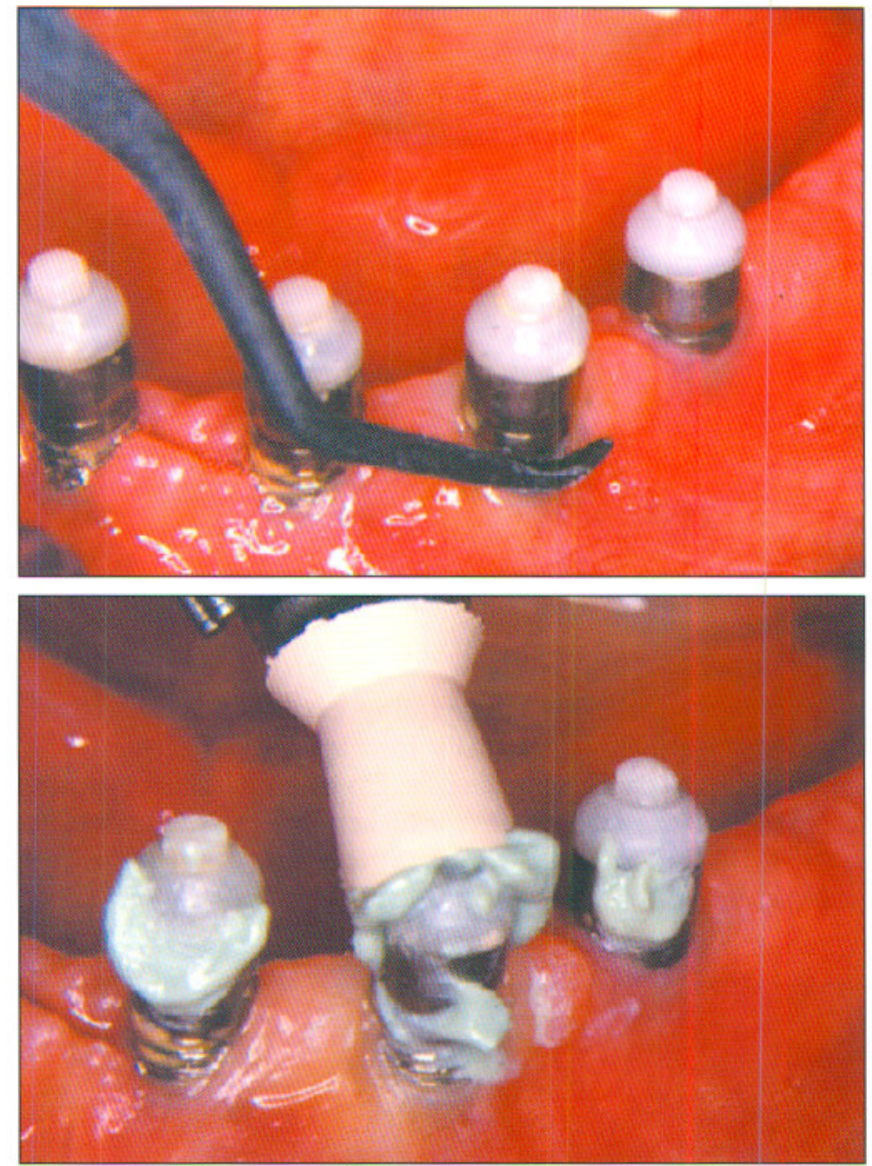

Fig. 12. Distintos momentos de la higiene profesional sobre los implantes.

hacerse especial hincapié en el control de placa para prevenir esta complicación (Figuras 11, 12, 13).

\subsection{Control de placa bacteriana}

Las recomendaciones e instrucciones en higiene oral en implantes que demos a nuestros pacientes estarán determinadas por la localización y angulación de los implantes, longitud y posición de los elementos transmucosos, del diseño de la prótesis así como de los hábitos del paciente, motivación, destreza manual y estado de salud oral. Por lo tanto, las instrucciones de higiene oral deben adecuarse a las peculiaridades de cada paciente.

En general se recomienda el uso de cepillo dental blando con pasta de diente poco abrasiva y el empleo cuidadoso de métodos de higiene en zonas interproximales (cinta dental, cepillo interproximal, cepillo unipenacho) (Figura 14). Los colutorios de clorhexidina están indicados en casos de periimplantitis o mucositis periimplantaria o bien en tratamientos de choque ante pacientes con higiene muy 

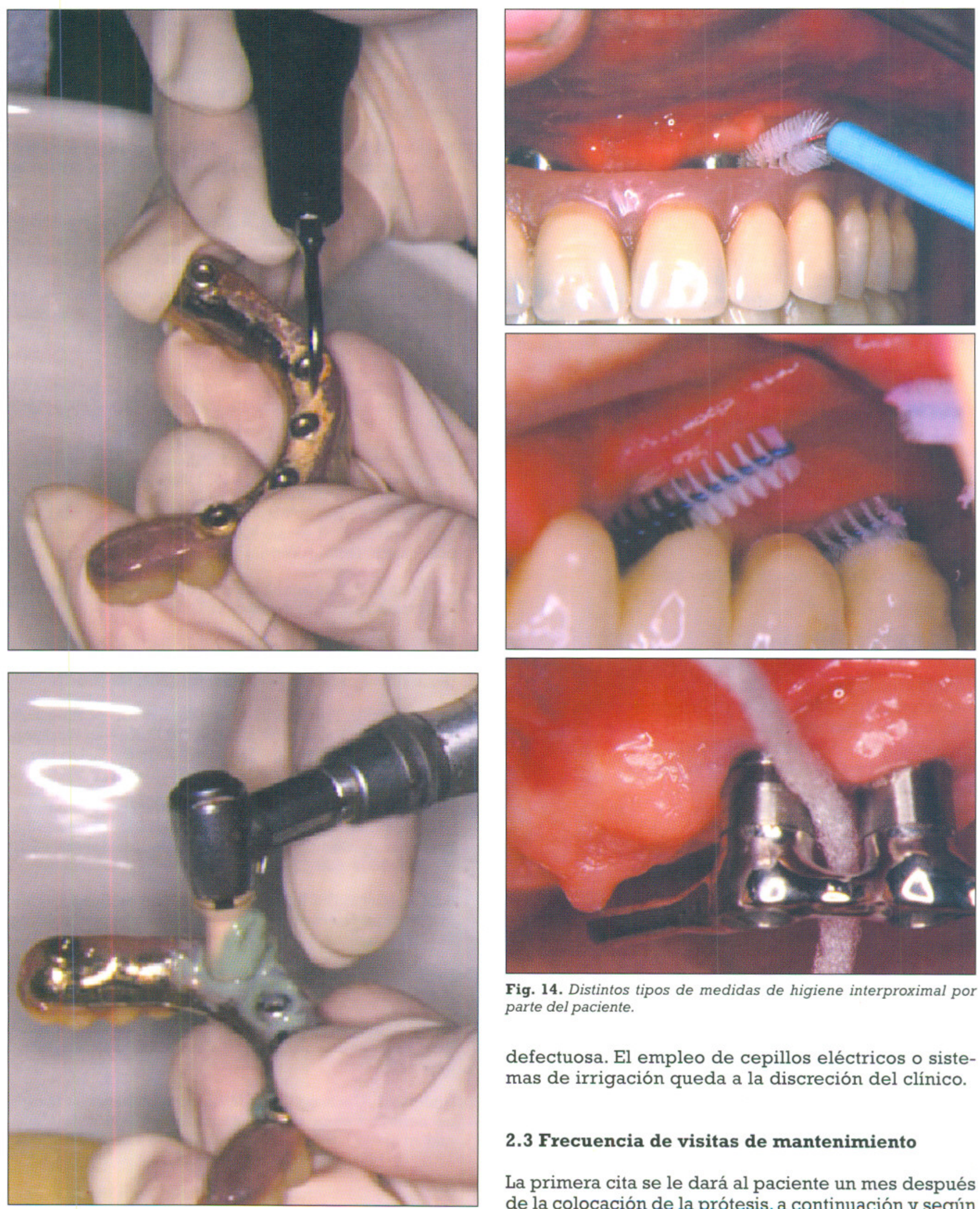

Fig. 14. Distintos tipos de medidas de higiene interproximal por parte del paciente.

defectuosa. El empleo de cepillos eléctricos o sistemas de irrigación queda a la discreción del clínico.

\subsection{Frecuencia de visitas de mantenimiento}

La primera cita se le dará al paciente un mes después de la colocación de la prótesis, a continuación y según

Fig. 13. Limpieza profesional de la prótesis implantosoportada. sus características recibirá de 2 a 5 sesiones con una 
frecuencia trimestral, para pasar en el desdentado total a un mantenimiento semestral cuando la higiene sea buena y no haya complicaciones. En pacientes parcialmente desdentados desde cuya flora periodontal, se pueden contaminar los implantes, será fundamental controlar las recidivas de la enfermedad periodontal, y para ello se recomienda mantener la periodicidad trimestral.

\section{SUMMARY}

The risk factors in periodontal and periimplant disease are determined, to establish how to prevent and control them. Different methods of patient monitorizing are described in detail, and so are the technicques to control the bacterian plaque.

The phases of periodontal and periimplant maintenance are analyzed.

\section{KEY WORDS}

Risk factors; Prevention; Maintenance.

\section{CORRESPONDENCIA}

\section{Dr. Victoriano Serrano Cuenca}

Departamento de Medicina y Cirugía Bucofacial.

Facultad de Odontología.

Universidad Complutense de Madrid.

Plaza Ramón y Cajal s/n. 28040 Madrid.

Teléfono y Fax: 914576298

\section{BIBLIOGRAFÍA}

1. Axelsson P. Needs related plaque control measures based on risk prediction. En: Lang NP, Attstrom R and Loe $\mathrm{H}$. Proceeding of the european workshop on mecanical plaque control. Quintessence books. Berlín.1998: 190247.

2. Beck JD, Koch GG, Offenbacher S. Incidence of attachment loss 3 years in older adults-new and progressing lesions. Community Dent Oral Epidemiol. 1995; 23: 2916.

3. Baca P. Enfermedades periodontales: Diagnóstico y prevención. En: Rioboo García R. Odontología Preventiva y Comunitaria. Avances Médico Dentales S.L. Madrid. 2002: 577-98.

4. Loe H, Theilade E, Jensen SB. Experimental gingivitis in man. J Periodontol 1965; 36:167-77.
5. Hart TC, Kornman KS. Genetic factors in the pathogenesis of periodontitis. Periodontology 2000 1997; 4: 202-15.

6. Salvi GE, Lawerence HP, Offenbacher S, Beck JD. Influence of risk factors on the pathogenesis of periodontitis. Periodontology 2000 1997; 14: 173-201.

7. Hernán M, March JC,Bimbela JL. Proceso de aprendizaje y educación para la salud. Escuela andaluza de Salud Pública. Granada 1996.

8. Inglehart M, Tedesco LA. Behavioral research related to oral hygiene practices: a new century model of oral health promotion. Periodontology 2000 1995; 8: 15-23.

9. Echeverría JJ, Manau C. Prevención y control de las enfermedades periodontales. En: Cuenca E y cols. Odontología Preventiva y Comunitaria. Masson. 1999: 153-69.

10. Sanders NL. Evidence-based care in orthodontics and periodontics: A review of the literature. JADA. 1999; 130: 521-7.

11. Offenbacher S. Periodontal diseases: Pathogenesis. Annals of Periodontology 1996; 1: 821-78.

12. Pilot T. Public health aspects of oral diseases and disorders. Periodontal diseases. En: Pine C, ed. Community oral health. Oxford: Wright 1997; 82-8.

13. Sheiham A. Public health aspects of periodontal diseases in Europe. J Clin Periodontol 1991; 18: 362-9.

14. Wilson T, Glover M, Schoen J, Baus C, Jacobs T. Compliance with maintenance therapy in a private periodontal practice. J Periodontol 1984; 55: 468-73.

15. Mombelli A. Prevention and therapy of periimplant infections. En Proceedings of the 3rd European Worksop on Periodontology. Eds Lang NP, Karring T, Lindhe J. Quintessence Books. Londres. 1999: 281-303.

16. Herrero M, Herrero F, Lázaro PJ. Prevención de la patología periimplantaria. En: Rioboo García R. Odontología Preventiva y Comunitaria. Avances Médico dentales S.L. Madrid. 2002: 599-621.

17. Bain C, Moy P. The Influence of smoking on bone quality and implant failures. Int.J Oral Maxillofac Implants. 1994; 9: 123 .

18. De Bruyn H, Collaert B. The effect of smoking on early implant failure. Clin Oral Impl Res. 1994; 5: 260-4.

19. Bain CA. Smoking and implant failure-benefits of a smoking cessation protocol. Int J Oral Maxillofac Implants. 1996; 11: 756-9.

20. Lindquist L, Carlsson G, Jem T. Association between marginal bone loss around osseointegrated mandibular implants and smoking habits: a 10 year follow-up study. J Dent Res. 1997; 76: 1667-74.

21. Weyant R. Characteristics associated with the loss and periimplant tissue health of endooseous dental implants. Int J Oral Maxillofac Implants. 1994; 5: 1-8.21 
22. Johnson GK, Fung YK,Squier CA. Effects of systemic administration of nicotine on capillaries in rat oral mucosa. J Oral Pathol Med 1989; 18: 230-2.

23. Tonetti MS. Risk factors for osseodisintegration. Periodontology 2000. 1998; 17: 55-62.

24. Apse P, Ellen R, Overall CM, Zarb GA. Microbiota and crevicular fluid collagenase activity in the osseointegrated dental implant sulcus: a comparison of sites in edentulous and partially edentulous patients. Journal of Periodontal Research 1989; 24: 96-105.

25. Mombelli A,Lang NP. Antimicrobial treatment of periimplant infections. Clinical Oral Implants Research 1992; 3: 149-155

26. Listgarten MA, Hellen L. Relative distribution of bacteria at clinically healthy and periodontally diseased sites in humans. Journal of Clinical Periodontology 1978; 5: 11532.

27. Rosemberg ES, Torosian JP, Slots J. Microbial differences in 2 clinically distinct types of failures of osseointegrated implants. Clinical Oral Implants Research 1991; 2: 13544.

28. Van Steenberghe D, Quirynen M, Callens A. The reactions of periodontal tissues to implants and teeth. In: Tissue Integration in Oral Orthopedic and Maxillofacial reconstruction. Quintessence. Chicago 1990: 41-7.

29. Ortega JJ, Bowen A, Carmona J, Benet F, González A. Patología periimplantaria. Gaceta Dental 2002; 125: 88132.

30. Offenbacher S, Hesman P, Collins J. Modulation of host PGE2 secretion as a determinant of periodontal disease. J Periodontol. 1995; 66: 150-7.

31. O'mahony A, Bowles Q, Woolsey G, Robinson SJ. Spencer P. Stress distribution in the single-unit osseointegrated dental implant: finite element analyses of axial and offaxial loading. Implant Dent 2000; 9: 207-18.

32. Isidor F. Loss of osseointegration caused by occlusal load of oral implants. A clinical and radiographic study in monkeys. Clin Oral Implants Res 1996; 7: 143-52.

33. Isidor F. Histological evaluation of peri-implant bone at implants subjected to occlusal overload or plaque accumulation. Clin Oral Implant Res 1997; 8: 1-9.

34. Tonetti MS, Schmid J. Pathogenesis of implant failures. Periodontology 2000. 1994; 3: 127-38.

35. Renouard F, Rangert B. En: Risk factors in implant dentistry. Chicago. Ed. Quintessence International; 1999; 1627.

36. Suárez MM, Suárez JM, Suárez J. Factores de riesgo en implantología. Revista Vasca de Odontoestomatología. 2001; 4: 16-25.
37. Bass SL, Triplett RG. The effects of preoperative resorption and jaw anatomy on implant success. A report of 303 cases. Clin Oral Implants Res 1991; 6: 193-8.

38. Jaffin R, Berman C. The excessive loss of Branemark implants in $\mathrm{t}$ yype IV bone. A five year analysis. J Periodontol. 1991; 62: 2-4.

39. Hutton J, Heath M, Chai J et al. Factors related to the success and failure rates at 3-year follow-up in a multicenter study of overdentures supported by Branemark implants. Int J Oral Maxillofac Implants. 1995; 10: 33-42.

40. Artzi Z, Tal H, Moses O, Kozlovsky A. Mucosal considerations for osseointegrated implants. J Prosthet Dent 1993; 70: 427-32.

41. Wennstrom JL, Bengazi F, Lekholm U. The influence of the masticatory mucosa on the peri-implant soft tissue condition. Clin Oral Implants Res 1994; 5: 1-8.

42. Wagner W, Esser E, Ostklamp K. Osseointegration of dental implants in patients with and without radiotherapy. Acta Oncol 1998; 37: 693-6.

43. Larsen PE. Placement of dental implants in the irradiated mandible: a protocol involving adjunctive hyperbaric oxygen. J Oral Maxillofac Surg 1997; 55: 967-71.

44. Karr RA, Kramer DC, Toth BB. Dental implants and chemotherapy complications. J Prosthet Dent 1992; 67:683-7.

45. Balshi TJ, Wolfinger GJ. Dental implants in the diabetic patient: a retrospective study. Implant Dent 1999; 8: 3559.

46. Olson JW, Shernoff AF, Tarlow JL, Colwell JA, Sheetz JP, Bingham SF. Dental endosseous implant assessments in a type 2 diabetic population: a prospective study. Int J Oral Maxillofac Implants 2000; 15: 811-8.

47. Lugero GG, De Falco V, Guzzo ML, Konig BJ, Jorgetti V. Histomorphometric evaluation of titanium implants in osteoporotic rabbits. Implant Dent 2000; 9: 303-9-

48. Bragger U. M. Maintenance, monitoring, therapy of implant failures. En Lang NP, Karring T eds. Proceedings of the lst European Workshop on Periodontology. London: Quintessence Publishing Co Inc, 1994: 345-64.

49. Noguerol B, Sicilia A. Terapéutica antimicrobiana en periodoncia. Tratamiento antimicrobiano de las complicaciones periimplantarias.En:Liébana J, Bagán JV. Terapéutica antimicrobiana en odontoestomatología. Madrid: IM\&C, 1996: 306-309.

50. Buitrago PJ, Gil FJ, Enrile FJ. El mantenimiento de implantes por el higienista dental. Periodoncia 2001; 1 1:409-20. 